\title{
1 The development of gestural communication in great apes
}

2

3 Marlen Fröhlich ${ }^{1 *} \&$ Catherine Hobaiter ${ }^{2}$

4

$5{ }^{1}$ Department of Anthropology, University of Zurich, Winterthurerstrasse 190, 8057 Zurich,

6 Switzerland

$7 \quad{ }^{2}$ School of Psychology and Neuroscience, University of St Andrews, St Marys College,

8 South Street, St Andrews KY16 9JP, Scotland.

9

$10 *$ Corresponding author; email address: marlen.froehlich@uzh.ch; telephone: +41 (0) 44635

115416

\section{Abstract}

Great apes deploy gestural signals in goal-directed and flexible ways across a wide range of social contexts. Despite growing evidence for profound effects of developmental experience on social cognition, socio-ecological factors shaping gesture use are still poorly understood, particularly in apes living in their natural environment. After discussing current ambiguities in terminology and methods, we review recent work implementing a longitudinal and/or cross-sectional approach in great ape gesture acquisition and development. To understand whether and to what extent the socio-ecological environment influences gestural communication, it is essential to distinguish between the gesture repertoire and gesture usage, which represent different levels of analysis. While the majority of the apes' gestural repertoire seems to be innate, accumulating evidence shows that the communicative usage of these signals is substantially affected by interactional experiences throughout ontogeny. 


\section{Keywords}

28 gesture, communication, development, repertoire, usage, great apes

\section{Significance statement}

31 Great apes navigate their differentiated social relationships by means of a large and flexible

32 repertoire of gestures. However, gestural ontogeny is still poorly understood, particularly in 33 primates living in their natural environment. We first discuss how the different usages of the

34 term 'gesture' have led to a number of apparently disparate views, but highlight that these

35 perspectives each provide their own contribution and may be reconciled by considering them

36 as different levels of explanation. We then review recent studies on the various individual and

37 social factors shaping the gestural use in great apes throughout development. While the

38 majority of the apes' gestural repertoire seems to be innate, the communicative usage of

39 these signals is substantially affected by interactional experiences throughout ontogeny.

40 Given that ape gestural signals are inherently multimodal and are then often combined with

41 other communicative signals, a broad multimodal perspective on gesture is important in order

42 to gain a thorough understanding of the developmental processes underlying great ape

43 communication. 
45 Gestural communication permeates practically every aspect of great apes' social lives.

Broadly defined as socially directed and mechanically ineffective bodily movements (e.g.

47 Cartmill and Byrne 2007; Hobaiter and Byrne 2011a; Pika 2008), gestures occur in everyday

communication across the full range of social contexts from meat-sharing and sex to joint travel and grooming and between all possible combinations of age-sex class relationships, for example: same-sex dyads during affiliation, social grooming, or travel (Douglas and Moscovice 2015; Goodall 1986; Pika and Mitani 2006); male-female dyads during consortship and mating (Genty and Zuberbühler 2014; Hobaiter and Byrne 2012) or motherinfant dyads in joint travel, food sharing, and social play (Bard 1992; Fröhlich et al. 2017; Halina et al. 2013; Plooij 1978).

Early descriptions of gesture use date back to the 1930s (for example: Ladygina-Kohts 1935; Ladygina-Kohts et al. 2002), and were included in the first field studies of chimpanzees (Goodall 1986; Plooij 1978; Plooij 1979; Plooij 1984; Van Lawick-Goodall 1968) and gorillas (Schaller 1963; Schaller 1965). Comparative gestural research was initially focused on great apes living in captive settings (chimpanzees, Pan troglodytes: Tomasello et al. 1985; Tomasello et al. 1989; Tomasello et al. 1994; Tomasello et al. 1997; gorillas, Gorilla gorilla: Tanner and Byrne 1996; Pika et al. 2003; bonobos, Pan paniscus: Pika et al. 2005; orangutans, Pongo abelii/pygmaeus: Liebal et al. 2006, Cartmill and Byrne 2007). These studies showed that great apes rely on gestures in their day-to-day intra-specific communication and possess extensive gestural repertoires (for review see: Call and Tomasello 2007). Great ape gestures qualify as intentional signals: irrespective of the species, methods, setting (field/captive), or research focus, across studies researchers find abundant evidence that gestures are regularly produced towards individual recipients in goal- 
oriented ways across a wide range of social contexts (e.g. Bard et al. 2014b; Byrne et al. 2017; Call and Tomasello 2007; Fröhlich et al. in press; Perlman et al. 2012; Roberts et al. 2014a). For example: gesturing is adjusted to the visual orientation of the target recipient (e.g., Cartmill and Byrne 2007; Leavens et al. 2005b; Liebal et al. 2004); signallers persist in, and sometimes elaborate, their gesturing until their goal is achieved (e.g. Cartmill and Byrne 2007; Leavens et al. 2005b; Hobaiter and Byrne., 2011b; Roberts et al. 2014b); and gestures are characterized by a flexible relationship between signal and outcome (means-ends dissociation), implying individual signallers are able to use different signals/gestures to achieve the same outcome/goal, or a single gesture for several outcomes (Graham et al., 2018; Liebal et al. 2006; Pika et al. 2003; Tomasello et al. 1994).

While the goal-oriented and flexible use of gestural signals by great apes is well established, less attention has been dedicated to the mechanisms underlying gesture acquisition and use during an individual's lifetime. A thorough understanding of development is critical for deciphering to what extent communication depends on input from the social and physical environment (Bard et al. 2014a; Liebal et al. 2013; Pika and Fröhlich 2018). In a pioneering study at the first established chimpanzee field site, Gombe in Tanzania, Frans Plooij (1978) described a sequence of communicative development in chimpanzee infants. Following Plooij's early work (1978; 1979), a number of studies explored gestural acquisition and development in captivity (Bard et al. 2014b; Halina et al. 2013; Savage-Rumbaugh et al. 1977; Schneider et al. 2012a; Schneider et al. 2012b; Tomasello et al. 1994; Tomasello et al. 1997; Tomasello et al. 1985; Tomasello et al. 1989). However, while captive studies provide opportunities for more fine-grained analyses, apes' behaviour and development may be substantially impacted by the physical and social environment afforded by captive settings (Bard 1992; Boesch 2007; Hobaiter and Byrne 2011a; Seyfarth and Cheney 2017; Tanner and 
94 Byrne 1996). To understand to what extent communicative development incorporates input from a range of socio-ecological environments, findings generated in captivity should be complemented by those of populations living in their natural environment (Boesch 2007).

Fortunately, the number of studies of gestures and gesturing in wild groups has also grown rapidly in recent years (e.g. Douglas and Moscovice 2015; Fröhlich et al. 2016a; Fröhlich et al. 2017; Fröhlich et al. 2016b; Fröhlich et al. in press; Genty et al. 2009; Graham et al. 2016, 2018; Hobaiter and Byrne 2011a; Hobaiter and Byrne 2011b; Hobaiter and Byrne 2012; Hobaiter and Byrne 2014; Pika and Mitani 2006; Roberts et al. 2014a; Roberts et al. 2012).

This review has two major objectives. First, we discuss how different operationalisations of the term 'gesture' have led to substantial variation between lines of gestural research. This variation makes direct comparability between studies challenging, but also highlights the importance of considering different perspectives in building a complete picture of gesture acquisition. Second, we review the breadth of recent research on the mechanisms that shape great ape gestural repertoires and the individual and social factors that impact their use during development.

\section{The problem with definitions: what is a 'gesture'?}

Despite decades of research, there remains no strict consensus on to how define a gesture.

Many researchers would probably agree that gestures include socially directed, mechanically ineffective movements of the extremities (e.g. Bard et al. 2014b; Cartmill and Byrne 2010; Fröhlich et al. 2016a; Hobaiter and Byrne 2011a; Pika 2008; Tomasello et al. 1997). Given that signals (as opposed to cues) are defined in evolutionary biology as traits that have been under selection specifically for their communicative function (Maynard Smith and Harper 2003; Ruxton and Schaefer 2011), this definition has led to many ambiguities. For example, 
studies including 'mechanical ineffectiveness' in their definition seldom specify whether it refers to the form or the outcome of a gesture (Perlman et al. 2012). Moreover, studies vary

121 in terms of whether gesture is restricted only to movements of the hand and fingers (Leavens

122 and Hopkins 1998; Leavens et al. 2010; Pollick and De Waal 2007; Roberts et al. 2014a;

123 Roberts et al. 2012), includes body postures and bodily movements (for example: bobbing,

124 rocking; Genty et al. 2009; Tanner and Byrne 1996), only includes actions qualified by

125 criteria of first-order intentionality, or incorporates different sensory modalities beyond the

126 visual channel.

128 The traditional dissociation of animal gesture from signals used in dynamic social displays by

129 the field of comparative psychology is a central concern. In most recent studies on gestural

130 communication, the 'gestures' described go beyond movements of the extremities to

131 encompass those of the entire body or even static body postures (e.g. Bard et al. 2014b;

132 Fröhlich et al. 2016a; Genty et al. 2009; Graham et al., 2016; Halina et al. 2013; Hobaiter and

133 Byrne 2011a; although cf. Pollick and de Waal 2007; Roberts et al. 2012). The distinction of

134 a gesture from a 'display' is only in the evidence for its intentional use. However, given that

135 the criteria for intentional use are typically not considered or explored in ethological

136 descriptions of displays, comparison across research fields and across taxa becomes

137 problematic. Take, for example, the 'leaf clip' gesture used by chimpanzees; outside of

138 gestural research it is typically categorized as a 'display' (Matsumoto-Oda and Tomonaga

139 2005; Nishida 1980), but within gestural research as a manual gesture with clear evidence for

140 intentional use (Hobaiter and Byrne 2011a; Hobaiter and Byrne 2012). In the opposite case

141 the 'hand-clasp' (a social signal used by chimpanzees in grooming) is often categorised as a

142 gesture in ethology (Arbib et al. 2008; Bard et al. 2014b; Pollick and De Waal 2007; Whiten

143 et al., 1999), but without any evidence for (or at least investigation of) its intentional use. 
144 What do we call a mechanically ineffective movement of the extremities that functions as a

145 signal, but without evidence that it is goal-directed? A vocalization researcher would not

146 label a chimpanzee vocal 'hoo' signal differently depending on the cognitive state of the

147 signaller, but a gesture researcher might (Liebal et al. 2014).

149 The emphasis on intentional use as a key criterion of a gestural signal stems from the excitement generated by the early demonstrations that great ape gestures were the first intentional communicative signals described outside of human language (Hewes 1973; Leavens and Hopkins 1998; Plooij 1978; Tomasello 2008). Today, most gestural researchers require that every token of signal use, irrespective of its physical similarity to previous cases of gesturing, be accompanied by some evidence of intentional use to be classified as a 'gesture'. So the distinction between categorising socially directed, goal-directed physical actions that meet the criteria for intentional gesture, and stereotyped and reflexive behavioural signals that do not (such as the mating displays of many birds), depends on our ability to detect intentional use. However, the detection and description of intentional signals remains the source of significant debate (Bar-On 2013; Moore 2015; Scott-Phillips 2015; Townsend et al. 2016). We have no access to a signaller's internal cognitive processes, and instead are reliant on external behavioural indications that together suggest intentional behaviour. These behavioural criteria for establishing intentional use typically refer to the

163 signaller's and/or recipient's visual attention - whether that be moving to produce a signal 164 within a recipient's line of sight, or visual monitoring of the recipient by the signaller during response waiting.

167 Here we face another issue in the description of a signal as a 'gesture' - modality. Gesture is 168 still frequently considered to be a primarily visual mode of communication, perhaps due to 
the fact that human gesture is generally investigated as action in visual space (Kendon 2004).

170 However, gestures can be perceived through three sensory channels: vision, hearing, and

171 touch. For those gestures with a salient, or even dominant, audible component (for example:

172 'slap object' or 'leaf clip') it can be challenging to establish intentional signal use because

173 they are frequently directed at non visually-attending recipients. Gesture is an intrinsically

174 multimodal form of communication (Cartmill and Byrne 2007; Fröhlich 2017; Hobaiter et al.

175 2017; Leavens and Hopkins 2005; Pollick et al. 2008), but at present the bias towards visual

176 attention in the definition of intentional signal use likely impacts both the range of signals

177 described as gestures, and our ability to detect intentional use in vocalizations and other

178 signal types.

179

180 The problem with definitions: What is ' $a$ ' gesture?

181 Comparative psychologists have typically focused on signal form in human and non-human

182 primates - particularly great apes - and refer to signal categories such as vocalization,

183 gesture, or facial expression as a 'modality' of communication. Multimodal signals are then

184 described as the simultaneous or sequential integration of signals from at least two of the

185 'modalities' (Liebal et al. 2014). However, outside of great ape communication, the term

186 'modality' is typically used to refer to the sensory modalities of vision, touch, hearing,

187 olfaction, etc. (Partan and Marler 2005; Rowe 1999). Behavioural ecologists, working across

188 a much wider range of species and taxa, are interested in the ultimate function of complex

189 signals and have typically focused on the senses employed to detect signals (Hebets and

190 Papaj 2005; Partan and Marler 1999b). Here multimodal signals are those that incorporate

191 multiple sensory modalities.

192 
193 A single gesture (for example a visual-audible 'slap object') thus contains multiple sensory 'modalities' from the perspective of a behavioural ecologist, but not from the perspective of a comparative psychologist (Fröhlich and van Schaik 2018). In contrast, a visual-silent gesture such as an 'arm wave' combined with a (visual) facial expression would be classified as

197 multimodal by a comparative psychologist, but unimodal (visual) to a behavioural ecologist

198 (Marler 1961; Partan and Marler 1999b; Wilson 1976). It is a mess. The different approaches contribute distinct and important parts of the picture; but the inconsistencies in the terminology makes subsequent comparison of hypotheses and data on 'multimodal' communication across taxa problematic, limiting our view of the wider whole. Comparative researchers, focused on the phylogeny of language-specific components like intentionality and reference, have justified their emphasis on the combination of multiple signals with the notion that different communicative categories, such as gestures and facial expressions, may have different underlying cognitive processes (Waller et al. 2013). However, comparative psychologists could extend the impact of their findings by realigning their terminology with that of the wider pre-existing literature. Recent studies of chimpanzee communication have started to explore these distinctions. Multimodality in a single signal is 'fixed' (a chimpanzee cannot produce the audible components of a pant-hoot vocalization, without also producing the visible facial movements), while multimodality in signal combinations (the addition of a visual-audible vocalization to a visual-silent gesture) is optional, and represents an

212 opportunity for 'flexible' communication (Davila-Ross et al. 2015; Fröhlich and van Schaik 213 2018). Signal combinations enable signallers to adapt their signalling to a specific physical or social environment (Hobaiter and Byrne 2017; Wilke et al. 2017). This distinction between

215 fixed and flexible combination of modes of information presents a fascinating new area for 216 testing the function of and cognitive prerequisites for different types of multimodal and 217 multicomponent communication in great apes. 


\section{Theories of gestural acquisition}

220 The ways in which individuals could acquire gestures during ontogeny (or not) has had

221 important implications for how developmental trajectories in gesture use were investigated.

222 Research on apes' gestural acquisition has been ongoing for several decades (e.g. Arbib et al. 2008; Liebal and Call 2012; Pika 2008), with a special issue on the topic published over the past year (Arbib and Gasser, in press; Bard et al. 2017; Byrne et al. 2017; Kersken et al., in press; Leavens et al. 2017; Liebal et al., 2018; Pika and Fröhlich 2018; Schneider et al. 2017; Tomasello and Call 2018), and so here we provide only a brief overview.

228 Researchers initially differentiated between individual and social (in particular imitation) learning processes of gesture acquisition (reviewed in Liebal and Call 2012). Building on Plooij's (1978) early descriptions of the 'social negotiation' of a behaviour into a signal (which he termed 'conventionalization'), Tomasello and colleagues developed the first

232 formal hypothesis of gestural acquisition, termed 'Ontogenetic Ritualization' (OR). They adapted the ethological concept of signal evolution over phylogenetic time ('ritualization'); in OR the forms that gestures take derive directly from repeated social interactions in which individuals participate through an individual learning process (Tomasello 1990; Tomasello et al. 1994). A series of studies, all conducted in captivity, found indirect support for this

237 hypothesis by reporting the presence of idiosyncratic gesture types (i.e. gesture types unique

238 to single individuals) and greater levels of similarity within, as opposed to between, groups

239 (Halina et al. 2013; Liebal et al. 2006; Pika et al. 2003; Pika et al. 2005). In contrast, any

240 evidence for the acquisition of gestural signals by imitation, or group-specific socially-

241 learned gesture types remained negligible (Byrne and Tanner 2006; Tanner and Byrne 1996;

242 Tomasello et al. 1997; Tomasello et al. 1989). Research in captive settings has shown that 
chimpanzee and bonobo infants share a considerably larger portion of their gestural repertoire

with individuals of their age group than with their mothers, further indicating that mothers' gestures are most likely not imitated (Schneider et al. 2012b).

246

247 Studies on great ape gestural communication in the wild (Genty et al. 2009; Hobaiter and

248 Byrne 2011a) presented apparently constrasting evidence for the existence of genetically

249 predisposed, species-specific gestural repertoires in great apes (Byrne et al. 2017). Finding an absence of idiosyncratic or group-specific gestures, significant overlap in species-repertoires, and a strong effect of observation time on individual repertoire size, these studies concluded

252 that the repertoire of signals available to great apes was phylogenetically ritualized, in a similar way to the repertoires of signals prevalent across animal and human communication

254 (Hobaiter and Byrne 2011a). In addition to the mechanisms of OR, imitation, and genetic endowment, Perlman and colleagues (2012) proposed that on-line ('real-time') adaptation of action is involved in the acquisition of ape gestures. By studying directive pushes during

257 travel coordination in a captive gorilla mother-infant pair, the authors concluded that these behaviours are 'molded to the physical affordances and social context of the moment of communication'. Bard and colleagues (2014b) examined gestural ontogeny in infant nurseryreared chimpanzees and found partial evidence for both OR and genetic endowment. Their results suggested that there are different modes of acquisition for different gesture types, with

262 the bulk of gestures co-constructed as a result of social interactions. This premise was further explored in the studies of Fröhlich and colleagues (Fröhlich et al. 2017; Fröhlich et al. 2016b; Fröhlich et al. 2016c) on the gestures that infant chimpanzees in two wild communities produce in interactions with their conspecifics. The authors found that social exposure and context play a substantial role for the gestural usage of young apes, and proposed a revised

267 theory of 'social negotiation' (Fröhlich et al. 2016c; Pika and Fröhlich 2018). The hypothesis 
states that gestures do not originate via shortening of a functional action sequence (contra the Ontogenetic Ritualization Hypothesis), but from the exchange of full-blown social

behaviours. This exchange results in a mutual understanding that certain behaviours can carry distinct meaning linked to particular social contexts and are produced to achieve distinct goals (Fröhlich et al. 2016c; Pika and Fröhlich 2018).

\section{Different perspectives on gesture and gestural ontogeny}

Studies on the onset and development of gestural communications in great apes have been heavily influenced by the diverging definitions of 'gesture' as used by the respective researchers. In the past decade, the debate about the acquisition of great ape gestures has pitted hypotheses that incorporate learning mechanisms and genetic predisposition against one another (Hobaiter and Byrne 2011a; Liebal and Call 2012). Here, we argue that the different theories could potentially be reconciled by reconsidering the perspectives taken on gestures and gesturing by the different groups of researchers as representing different levels of explanation (see also Liebal et al. 2018). For example: all groups of gesture researchers describe a gesture type (or category) ‘touch' - common across all individuals (and indeed all ape species; Call and Tomasello 2007; Hobaiter and Byrne 2011a) - this could be classified as a phylogenetically ritualized gesture. However, at the same time, the specific form of this gesture as produced by any one individual, or in any specific interaction, may vary substantially in the orientation of the signallers movement, or the location of contact to the recipient (Bard et al. 2017; Perlman et al. 2012; Tanner and Byrne 1996), showing 'real time adaptation' (Perlman et al. 2012) and/or 'social negotiation' (Pika and Fröhlich 2018) of the exact form in a specific interaction. Similarly, the gestural 'repertoires' of two individuals can be measured at a specific point in time or developmental stage and be found to differ

292 dramatically (e.g. Schneider et al. 2012b); but, over a lifetime, the available 'repertoire' of 
gestures expressed by the two individuals may be identical. We can also distinguish the way in which an ape produces the gesture, or the way in which a gesture is understood (Hobaiter and Byrne 2017). Hence, depending on the level of explanation investigated, 'a' gesture or 'a' repertoire might refer to something fundamentally different.

298 As a result, the apparent differences in the nature of gesture acquisition may have emerged from a focus on different levels of explanation of the gestural system. Many species have a biologically available repertoire of signals. In human language we could consider this to be phonemes - a set of sounds that all humans can produce or discriminate in very early infancy

302 (Kuhl 2003; Kuhl 2004; Ruben 1997). These are our species-typical repertoire of sounds.

303 Similarly we can ask the question: what are the available species-typical repertoires of ape gestures, the set of gestures that all apes could produce or discriminate (Byrne et al. 2017; one specific communicative event, the use and expression of this available repertoire will vary. In human language, with its cultural diversity of sounds, words, and structures, our phonemes are rapidly channelled through early experience (Kuhl 2004; Ruben 1997). We are left with an individually- and culturally-specific subset of sounds with which we communicate on a day-to-day basis. Within these, the expression of these sounds in any specific instance of communication may again vary. Any two examples of even a single

312 simple word produced by the same individual likely vary in tone, pitch, and emphasis (e.g.

313 Scherer 1995). Within a species-typical available repertoire of great ape gestures, particular pairs of individuals - such as mothers and infants - may regularly employ a subset of

315 gestures to communicate a goal (Fröhlich et al. 2017; Fröhlich et al. 2016c; Halina et al. 2013; Perlman et al. 2012). And, in any one specific instance of gestural communication, the 
317 precise deployment of a gesture may vary in its physical form, or where contact may be made 318 with the recipient (e.g. Bard et al. 2017).

319

320 As in any ethological study of behaviour, no individual approach to the study of gesture is

321 'correct' in providing a more accurate explanation than others - a complete understanding of how gestural signals are acquired and deployed is only acquired across the different levels of explanation (Tinbergen 1963). In the study of available gestural repertoires, the focus lies on the study of gesture as a system (i.e. at the level of the 'tool-set' available), in the study of gesturing the focus lies on the use of specific cases within the system (i.e. at the level of the 'tool application'). Moreover, signal production, communicative usage, and comprehension may all show different developmental pathways, which might be in turn suggestive of different cognitive prerequisites (Liebal et al. 2014). Here, interestingly, the variation in the physical and social environment in which captive and wild chimpanzees develop may have contributed to some of the variation in findings between studies. If the available forms of gesture types are vertically transmitted via genetic endowment, the selection of gesture types, and the appropriate use and response to these gestures may still be learned and affected by development. In other words, although some components of gestures might withstand different rearing environments, others may vary with variation in socio-ecological experiences during development (Fröhlich et al. 2017; Hobaiter and Byrne 2011b; Liebal et al. 2014).

\section{Available gestural repertoires: innate and family-typical}

In recent studies on the gestural communication of chimpanzees and gorillas, Byrne and colleagues (Genty et al. 2009; Hobaiter and Byrne 2011a) proposed that apes' available

341 gestural repertoires are biologically 'hard-wired' and mainly derived from genetic 
342 inheritance. The St Andrews gesture group has identified an array of gesture types commonly

343 found across ape species, providing evidence that large sections of these gestural repertoires

344 are in fact family-typical (Cartmill and Byrne 2010; Genty et al. 2009; Graham et al. 2016;

345 Hobaiter and Byrne 2011a). These species- and family-typical repertoires of gestures are

346 consistent in basic form throughout development (for example 'arm raise'; Genty et al. 2009;

347 Hobaiter and Byrne 2011a). However, they may be expressed flexibly by specific individuals,

348 or in a specific interaction (for example - in the orientation of the arm and hand). While it

349 remains possible that large species-typical repertoires of gestures could be acquired through

350 social learning, ontogenetic ritualization, or even imitation, biological inheritance provides

351 the most parsimonious explanation - particularly given the prevalence of genetically

352 channelled repertoires of signals across other species, including humans (Kuhl 2003; Kuhl

353 2004; Ruben 1997). Even human communication, with its diversity of sounds, words, and

354 structures, is founded on a shared genetically channelled set of phonemes - available to all

355 individuals at birth, but rapidly channelled through early ontogenetic experience (Kuhl 2003;

356 Kuhl 2004; Ruben 1997).

357

358 One criticism of this approach to the study of gesture has been that, given the natural

359 anatomical constraints of a shared body plan across great apes, gestural repertoires will be

360 inevitably similar in form no matter what the acquisition mechanism. Apes share the same

361 basic body plan, and there are only so many ways you can move a body of this type.

362 However, a recent exploration of chimpanzee gestures showed that only around $12 \%$ of the

363 physically possible gesture forms were expressed in the chimpanzee repertoire (Hobaiter and

364 Byrne 2017). Byrne and colleagues thus made a strong case for the notion that the majority of

365 gesture types in the available ape repertoire are biologically inherited and, with an extensive 
overlap in repertoire across all great ape genera, their phylogenetic origin is thus argued to be relatively old (Byrne et al. 2017).

368

369 One challenging aspect to describing the available repertoire is discriminating different

370 gesture types. For example: the gesture 'touch', used as a label across many studies, may or may not include the gesture types: stroke, light touch, etc. (Hobaiter and Byrne 2011a). One recent study distinguished 36 forms of this single 'gesture' (Bard et al. 2017). Should we discriminate a 'hand shake' from an 'arm shake', an 'arm swing' from a 'leg swing'? Again, there is no 'correct' approach. The appropriate level of discrimination depends on the question being asked. One approach employed by Hobaiter and Byrne (2017) has been to use ape behaviour to guide the process. If apes employ two 'types' of gesture to consistently achieve the same goal, we can make the case that - from the apes' perspective - they are a single gesture 'type'. After splitting gesture forms to a highly detailed level (resulting in 1005 possible gesture types), gestures were lumped into 'types' based on consistencies in the apes' behavioural responses, resulting in a repertoire of 81 gesture types in chimpanzees.

\section{Gestural usage: shaped by interactional experiences}

383 Evidence that the available gestural repertoires of great apes are largely innate (Byrne et al. 2017) does not prevent considerable modification of and flexibility in gestural usage throughout an individual's life time (Hobaiter and Byrne 2011b; Pika and Fröhlich 2018). Previous studies in both captive (Bard et al. 2014b; Bard et al. 2017; Schneider et al. 2012a; Schneider et al. 2012b; Tomasello et al. 1994; Tomasello et al. 1997; Tomasello et al. 1989) and wild settings (Fröhlich et al. 2017; Fröhlich et al. 2016b; Fröhlich et al. 2016c; Hobaiter and Byrne 2011b; Plooij 1978; Van Lawick-Goodall 1968) suggested that the development of gesture usage in chimpanzee infants is linked to entering their social world and the 
opportunities it affords to interact with conspecifics. Given that communication takes place in a wide range of social and physical environments, in many behavioural contexts, and over an individual's lifetime, it is likely that individuals rely on input from their social environment before communicative skills fully manifest (Liebal et al. 2014). Bard and colleagues (2014b) examined gestural ontogeny in nursery-reared chimpanzees and suggested that the majority of gestures used by individuals emerge through co-construction as a result of social interactions. In a study carried out in two communities of wild chimpanzees, Fröhlich et al. (2016c) found evidence for considerable inter-individual variation in the mothers' gestural repertoires used to initiate joint travel with their offspring. Another study focusing on three different communicative contexts—-food-sharing, joint travel, and social play-examined the role of social exposure, namely behavioural context, interaction rates, and maternal proximity, for infant gestural production (Fröhlich et al. 2017). Interestingly, the rate of previous interaction with conspecifics, but not with their mothers, had a positive effect on gestural frequency and repertoire. Indeed, the number of gesture types used by infants (aged between 9 and 69 months) increased with the number of interaction partners in the previous month of life. The empirical link between social exposure and gestural performance suggests that learning via repeated social interactions shapes the communicative development of gesturing in young apes (see also Bard et al. 2014b). While the mother-infant relationship is critical for normal social development (Maestripieri 2009), early socialization in the wider

410 social environment seems to be essential to develop social competency later in life (Hamilton 411 2010; Parker and Asher 1987). In sum, accumulating work across studies and sites suggests that communicative development is reliant on the infants' early social environment (e.g.

413 Fröhlich et al. 2017; Hobaiter and Byrne 2011b; Van Lawick-Goodall 1968).

\section{The developmental trajectory in gestural communication}


416 In contrast to the mechanisms of acquisition, the age of emergence and developmental

417 trajectory in gesturing appears less controversial. In the first longitudinal study of

418 chimpanzees at Gombe, Goodall $(1967 ; 1986)$ noted that bodily signals in the first few

419 months of life are limited to variations in body contact for mother-infant coordination. Plooij

420 (1978), later focusing on communicative development in the same community, observed a

421 gradual transition towards goal-oriented and voluntary ('illocutionary') communication in

422 chimpanzees between nine and twelve months, in a similar manner to human infants (Bates et

423 al. 1979; Bates et al. 1975). During this transition, chimpanzee infants gradually began to

424 deploy intentionally communicative gestures to influence the behaviour of conspecifics, and

425 to initiate interactions such as play and grooming.

426

427 In a captive setting, Schneider and colleagues (2012a) investigated gestural onset and the emergence of tactile, visual, and auditory gesturing in all four great ape genera. As seen in wild chimpanzees, infants of the three African ape genera (chimpanzee, bonobo, and gorilla)

430 started gesturing towards the end of their first year. Orang-utan infants showed a later onset, 431 only starting to gesture at around 15 months of age, perhaps reflecting their slower life 432 histories (van Noordwijk and van Schaik 2005; Wich et al. 2004). While tactile and visual 433 gestures emerged at around the same time and were used in similar proportions in the first 434 months of gesturing, auditory gestures emerged significantly later in the African ape genera 435 and were not observed in the orang-utan infants studied (Schneider et al. 2012a). The

436 findings from captive settings are complemented by studies on different chimpanzee communities in the wild, showing that young chimpanzees undergo a developmental shift

438 from actions and tactile gestures to visual communication (Fröhlich et al. 2016c; Plooij 439 1978), and an increase in auditory communication with infant age (Fröhlich et al. 2016b). 
440 This incorporation of visual and auditory signals may reflect the infant apes' increasing

441 physical and social independence from their mothers.

442

\section{The effects of context and sex on early gestural communication}

444 Previous research on gesture development suggests that social play is the major context of 445 gesture usage in young African apes (Fröhlich et al. 2017; Genty et al., 2009; Hobaiter and 446 Byrne 2011b; Schneider et al. 2012a; Tomasello et al. 1997). Play interactions with peers

447 and other 'non-mother' individuals may serve as essential platform for experimentation, 448 where great apes can test for the effectiveness of intentional gestures that might gain vital 449 importance in their adult life (Fröhlich et al. 2016b). Early gestural communication also appears to play a substantial role for the solicitation of food transfers by young apes (Fröhlich et al. 2017; Pika et al. 2003; Pika et al. 2005), especially in orang-utans (Bard 1992; Schneider et al. 2012a). Communicative exchanges related to desirable objects (e.g. Hobaiter et al. 2013; Pika and Zuberbühler 2008) may be particularly interesting, as they represent

454 'triadic' interactions, involving a signaller, recipient, and a third entity - prerequisites for the 455 development of referential communication (Leavens et al. 2005a; Pika 2012)

457 Recent studies of chimpanzee development have highlighted sex differences in the importance of early socialization in chimpanzees (Murray et al. 2014). In the fission-fusion

459 social structure characteristic of wild chimpanzees (Aureli et al. 2008), the mother can 460 actively influence their offspring's social environment through selective subgrouping 461 (Lonsdorf et al. 2014a). From a very early age, male chimpanzees in particular seem to exploit these social opportunities, with the number of social partners of males increasing with

463 offspring age and distance to the mother (Lonsdorf et al. 2014a; Lonsdorf et al. 2014b).

464 These social differences are reflected in sex differences in infant chimpanzee gesturing. For 
example: male infants deployed more contact gestures than females to solicit play (Fröhlich et al. 2016b) and request food transfers (Fröhlich et al. in prep); and, after controlling for age, used a larger variety of gesture types (Fröhlich et al. 2017).

\section{Towards a multimodal approach to communicative development}

In the wider animal communication literature, developmental work has tended to focus on either the vocal or gestural modality independently, with the bulk of work on acquisition carried out on song learning in songbirds (e.g., Beecher and Brenowitz 2005; Brainard and Doupe 2002; Marler 1997). Studies of vocal development in birds and mammals have demonstrated that individual experiences accumulated through social interactions (e.g. responses of conspecifics) can play a substantial role by introducing new sounds and encouraging improvisation (Snowdon and Hausberger 1997). Gros-Louis and colleagues (2006) argued that vocal development in human infants is also shaped by social interactions, but acknowledge that the specific links between social context and pre-linguistic vocal development are understudied (Vihman 1996). Some studies have explored the developmental trajectories of different sensory modalities within ape gesturing (Fröhlich et al. 2016b; Fröhlich et al. 2016c; Schneider et al. 2012a). However, it is crucial to keep in mind that gestures represent part of apes' larger repertoire of communicative signals, which includes vocalisations and facial expressions (Liebal et al. 2014). For a more thorough understanding, it is critical to investigate the impact of socio-ecological factors on communicative development in a holistic fashion, across production modes and sensory modalities (Fröhlich and van Schaik 2018; Hobaiter et al. 2017; Liebal et al. 2014).

In primates, little is known about whether and how the developmental trajectories of multimodal (or multicomponent) signals (in which two or more components of different sensory modalities must be produced together in order to produce the individual signal) and 
multimodal signal combinations (in which two distinct signals, which incorporate different sensory modalities, are flexibly coupled) differ from unimodal signalling (Bard et al. 2014b; Gillespie-Lynch et al. 2014; Liebal et al. 2014). Some developmental research on multimodal integration has focused on audio-visual perception in human and non-human primates, whereas multimodal production remains understudied (reviewed in Partan 2013). Even less is known about the development of multimodal signal combinations (Fröhlich and van Schaik 2018). In light of an increasing body of work that demonstrates a substantial impact of social experiences on socio-cognitive and communicative development (Bard et al. 2014b; Fröhlich et al. 2017; Katsu et al. 2017; Laporte and Zuberbühler 2011; Snowdon and Hausberger 1997), it is vital to understand the role of learning and social experience in both unimodal and multimodal signal production (see also Higham and Hebets 2013).

Early explorations of a multimodal or multi-signal approach to chimpanzee communication have found strong effects of age on signal choice (Hobaiter et al. 2017; Wilke et al. 2017), with a bias towards gestural communication in early infancy (e.g. Fröhlich et al. in press; Gillespie-Lynch et al. 2013; Hobaiter et al. 2017). Fröhlich et al. (in press) explored the developmental trajectories of established behavioural markers of intentional communication in apes on a study of infants' gestures, actions, vocalizations and 'bi-modal combinations' (gesture plus vocalization). The authors found that proportions of association with audience checking, goal persistence and sensitivity to the recipient's visual orientation increase with infant age. However, context, interaction partner, and sub-species also impact the selection of signal types, as well as the behavioural markers of intentional communication, strongly suggesting that the social environment urgently needs to be considered in studies of communicative development (Fröhlich et al. in press). 
516 The 'backup signal' hypothesis, initially invoked by behavioural ecologists for multimodal

517 signals, implies that the different components of complex signals are redundant, that is they

518 elicit the same response in the receiver (Møller and Pomiankowski 1993; Partan and Marler

519 1999a). Similarly, multimodal signal combinations might be part of a learning process in

520 communicative development in which the immature ape learns to deploy context-appropriate

521 communicative tactics by first using redundant signals sequentially and/or simultaneously

522 (Fröhlich and van Schaik 2018; Liebal et al. 2014). Some support for this explanation comes

523 from studies on chimpanzees. Hobaiter and Byrne (2011b) found that chimpanzees gradually

524 shift from initially long and largely redundant gestural sequences to selecting more effective

525 single gestures as adults. A recent study on joint travel initiation in mother-infant pairs

526 suggested a developmental shift from multimodal (audible 'hoo whimper' vocalizations

527 combined with visual gestures) to unimodal signalling (visual gestures only) in infant

528 chimpanzees (Fröhlich et al. 2016c). There appears to be many more gestures in great ape

529 repertoires than meanings for which they are used (Graham et al. 2018; Hobaiter and Byrne

530 2014); this redundancy may offer signalers the opportunity to select different sensory

531 modalities in which to communicate similar information. However, the restricted range of

532 meanings described might also result from how observers currently classify 'meaning' (for

533 example: requiring a visible behavioural change by the recipient) rather than from a naturally

534 constrained set of meanings (Hobaiter and Byrne, 2014; Bard et al. 2017).

535

536 An alternative explanation for the combination of signals and modalities is proposed by the

537 theories of refinement and complementarity (e.g. Fröhlich and van Schaik 2018; Genty et al.,

538 2014; Hobaiter et al., 2017; Jacob et al., 2011; Partan and Marler, 2005). Recent studies of

539 chimpanzee and bonobo communication suggest that vocal and gestural signals are not used

540 interchangeably. Chimpanzee gesture-vocal signal combinations were more likely to elicit a 
541 behavioural response than vocal signals, but not as compared to gestural signals (Wilke et al.

542 2017). Similarly, chimpanzees were more likely to switch to gesture-vocal combinations

543 following the failure of a vocal signal but not a gestural one (Hobaiter et al. 2017).

544

545 Apart from the sensory modality in which information is transmitted, the type of information

546 is also a key consideration, for example: bonobos employ gestural signals to differentiate the

547 context in which an ambiguous vocal signal is used (Genty et al. 2014). In chimpanzees,

548 while all vocalizations and some gestures convey information in the auditory modality,

549 vocalizations (and possibly buttress-drumming gestures; Arcadi et al. 1998) also encode the

550 identity of the signaller. This feature may impact their use depending on the potential risk of

551 'eavesdroppers' acquiring the information being transmitted (Hobaiter and Byrne 2012;

552 Hobaiter et al. 2017).

553

554 If the different signal types or signal components of multimodal communication are

555 combined in order to refine or complement a core message, then we would predict that single

556 components and signals precede the use of more complex communication during

557 development. However, substantial comparative work focusing on the ontogeny of

558 multimodal production in nonhuman primates is needed to reveal what role multimodal

559 signal combinations play throughout development, and across social roles that themselves

560 change across ape lifetimes.

561

562

563 Conclusion

564 In this review we provide an overview of recent work on gestural ontogeny in great apes. We

565 suggest that apparently disparate views on the fixed or flexible nature of ape repertoires may 
566 be reconciled by considering them to be different levels of explanation, and that subtle

567 differences in the use of terminology between studies and fields may be at the root of

568 apparently contradictory findings. A gesture type may be species-typical, but its specific

569 expression in day-to-day gesturing may be highly flexible. The 'repertoire' of two individuals

570 may differ dramatically when measured over a month, or even a year, but may match when

571 measured over a lifetime. While available repertoires appear largely innate and species-

572 typical, inter-individual differences in gesture usage suggest an important role for learning,

573 mirroring the current state of knowledge on primate vocalizations (Cheney and Seyfarth

574 2018). For any particular instance of gesturing, individual and social variables including at

575 least: partner identity, age, sex, rank, physical location, visual attention, social and biological

576 relationship, as well as the wider behavioural context determine which gestures are selected

577 from the communicative tool set and how they are deployed. The increasing evidence for the

578 impact of the social environment on gesturing represents both a challenge and an opportunity

579 for comparative studies of behaviour and cognition.

580

581 To develop a more thorough understanding of the socio-ecological factors shaping the communicative use of gesture, we can make use of an explicitly multimodal multicomponent approach. Short-range communication in great apes is inherently multimodal; 'visual'

584 gestures frequently have salient tactile and audible components, just as vocalisations have

585 visual components (Liebal et al. 2014). More comparative work focusing on the ontogeny of

586 multimodal production in nonhuman primates is needed to reveal what role multimodal

587 signal combinations plays in developmental. In turn, this might shed new light on the cognitive processes underlying ape communication, allowing us to develop our understanding

589 of the evolutionary continuity between non-human and human multimodal communication. 
592 Acknowledgements

593 We are grateful to Federica Amici and Anja Widdig for their invitation to the special issue 594 "An evolutionary perspective on the development of primate sociality". We thank Simone 595 Pika, Carel van Schaik, Maria van Noordwijk, Richard Byrne, and the whole St Andrews 596 Gesture group for many insightful discussions on great ape gestures.

597

\section{$598 \quad$ Funding}

599 M.F. was funded by the Forschungskredit of the University of Zurich, grant no. FK-17-106.

600

601 Conflict of Interest

602 The authors declare that they have no conflict of interest.

603

604 Ethical approval

605 This article does not contain any studies with human participants or animals performed by 606 any of the authors.

607

608 Informed consent

609 For this type of study formal consent is not required.

610

611 References

612 Arbib MA, Gasser B (in press) A dyadic brain model of ape gestural learning, production and 613 representation. Animal Cognition.

614 Arbib MA, Liebal K, Pika S (2008) Primate vocalization, gesture, and the evolution of 615 human language Current Anthropology 49:1053-1063 doi:10.1086/593015 
616 Arcadi AC, Robert D, Boesch C (1998) Buttress drumming by wild chimpanzees: Temporal

617

618

619

620

621

622

623

624

625

626

627

628

629

630

631

632

633

634

635

636

637

638

639

640 patterning, phrase integration into loud calls, and preliminary evidence for individual distinctiveness Primates 39:505-518

Aureli F et al. (2008) Fission- fusion dynamics Current Anthropology 49:627-654

Bar-On D (2013) Origins of meaning: Must we 'go Gricean'? Mind \& Language 28:342-375

Bard KA (1992) Intentional Behavior and Intentional Communication in Young FreeRanging Orangutans. Child Development 63:1186-1197 doi:10.1111/j.14678624.1992.tb01688.x

Bard KA, Bakeman R, Boysen ST, Leavens DA (2014a) Emotional engagements predict and enhance social cognition in young chimpanzees Developmental Science 17:682-696 doi:10.1111/desc. 12145

Bard KA, Dunbar S, Maguire-Herring V, Veira Y, Hayes KG, McDonald K (2014b) Gestures and social-emotional communicative development in chimpanzee infants American Journal of Primatology 76:14-29 doi:10.1002/ajp.22189

Bard KA, Maguire-Herring V, Tomonaga M, Matsuzawa T (2017) The gesture ‘Touch': Does meaning-making develop in chimpanzees' use of a very flexible gesture? Anim Cogn:1-16

Bates E, Benigni L, Bretherton I, Camaioni L, Volterra V (1979) The Emergence of Symbols: Cognition and Communication in Infancy. Academic Press, New York

Bates E, Camaioni L, Volterra V (1975) The acquisition of performatives prior to speech Merrill-Palmer Quarterly: Journal of Developmental Psychology 21:205-226

Beecher MD, Brenowitz EA (2005) Functional aspects of song learning in songbirds Trends in Ecology \& Evolution 20:143-149

Boesch C (2007) What makes us human (Homo sapiens)? The challenge of cognitive crossspecies comparison Journal of Comparative Psychology 3:227-240 
641 Brainard MS, Doupe AJ (2002) What songbirds teach us about learning Nature 417:351-358

642 Byrne RW, Cartmill E, Genty E, Graham KE, Hobaiter C, Tanner J (2017) Great ape gestures: intentional communication with a rich set of innate signals Anim Cogn

644 20:755-769 doi:10.1007/s10071-017-1096-4

645 capacity International Journal of Psychology and Psychological Therapy 6

647 Call J, Tomasello M (2007) The gestural communication of apes and monkeys. Lawrence 648 Erlbaum Associates, Mahwah, New York

649

Cartmill E, Byrne R (2010) Semantics of primate gestures: intentional meanings of orangutan gestures Anim Cogn 13:793-804 doi:10.1007/s10071-010-0328-7

651

Cartmill EA, Byrne RW (2007) Orangutans modify their gestural signaling according to their 652 audience's comprehension Curr Biol 17:1345-1348 doi:10.1016/j.cub.2007.06.069

Cheney DL, Seyfarth RM (2018) Flexible usage and social function in primate vocalizations Proceedings of the National Academy of Sciences doi:10.1073/pnas.1717572115

Davila-Ross M, Jesus G, Osborne J, Bard KA (2015) Chimpanzees (Pan troglodytes) produce 656 the same types of 'laugh faces' when they emit laughter and when they are silent PloS

657 one 10:e0127337

658

Douglas PH, Moscovice LR (2015) Pointing and pantomime in wild apes? Female bonobos

659

660 use referential and iconic gestures to request genito-genital rubbing Sci Rep 5 doi:10.1038/srep13999

661 662 communication Neuroscience \& Biobehavioral Reviews 80:201-209

663

Fröhlich M, Kuchenbuch P, Müller G, Fruth B, Furuichi T, Wittig RM, Pika S (2016a)

664 Unpeeling the layers of language: Bonobos and chimpanzees engage in cooperative 665 turn-taking sequences Sci Rep 6:25887 
666 Fröhlich M, Müller G, Zeiträg C, Wittig RM, Pika S (in prep) Knowing when to invest

667

668

669

670

671

672

673

674

675

676

677

678

679

680

681

682

683

684

685

686

687

688

689

communicative effort: Food solicitation by young chimpanzees in the wild

Fröhlich M, Müller G, Zeiträg C, Wittig RW, Pika S (2017) Gestural development of chimpanzees in the wild: The impact of interactional experience Animal Behaviour doi:http://dx.doi.org/10.1016/j.anbehav.2016.12.018

Fröhlich M, van Schaik CP (2018) The function of primate multimodal communication Anim Cogn:1-11 doi:10.1007/s10071-018-1197-8

Fröhlich M, Wittig RM, Pika S (2016b) Play-solicitation gestures in chimpanzees in the wild: flexible adjustment to social circumstances and individual matrices Royal Society Open Science 3:160278

Fröhlich M, Wittig RM, Pika S (2016c) Should I stay or should I go? Initiation of joint travel in mother-infant dyads of two chimpanzee communities in the wild Anim Cogn 19:483-500 doi:10.1007/s10071-015-0948-Z

Fröhlich M, Wittig RM, Pika S (in press) The ontogeny of intentional communication in wild chimpanzees Developmental Science

Genty E, Breuer T, Hobaiter C, Byrne RW (2009) Gestural communication of the gorilla (Gorilla gorilla): Repertoire, intentionality and possible origins Anim Cogn 12:527546 doi:10.1007/s10071-009-0213-4

Genty E, Clay Z, Hobaiter C, Zuberbühler K (2014) Multi-Modal Use of a Socially Directed Call in Bonobos PLoS ONE 9:e84738 doi:10.1371/journal.pone.0084738

Genty E, Zuberbühler K (2014) Spatial Reference in a Bonobo Gesture Curr Biol doi:http://dx.doi.org/10.1016/j.cub.2014.05.065

Gillespie-Lynch K, Greenfield P, Feng Y, Savage-Rumbaugh S, Lyn H (2013) A CrossSpecies Study of Gesture and Its Role in Symbolic Development: Implications for the 
692 Gillespie-Lynch K, Greenfield PM, Lyn H, Savage-Rumbaugh S (2014) Gestural and 693 symbolic development among apes and humans: support for a multimodal theory of language evolution Frontiers in Psychology 5:1228 doi:10.3389/fpsyg.2014.01228

Goodall J (1986) The chimpanzees of Gombe: Patterns of behaviour. The Belknap Press of Harvard University Press, Cambridge, England

697

Graham K, Hobaiter C, Ounsley J, Furuichi T, Byrne RW (2018) Bonobo and chimpanzee gestures overlap extensively in meaning PLoS Biology 16:e2004825

Graham KE, Furuichi T, Byrne RW (2016) The gestural repertoire of the wild bonobo (Pan paniscus): a mutually understood communication system Anim Cogn:1-7

Gros-Louis J, West MJ, Goldstein MH, King AP (2006) Mothers provide differential

702 feedback to infants' prelinguistic sounds International Journal of Behavioral Development 30:509-516 doi:10.1177/0165025406071914

Halina M, Rossano F, Tomasello M (2013) The ontogenetic ritualization of bonobo gestures Anim Cogn:1-14 doi:10.1007/s10071-013-0601-7

707

Hamilton SF (2010) Apprenticeship for adulthood. Simon and Schuster, New York

Hebets EA, Papaj DR (2005) Complex signal function: Developing a framework of testable 708 hypotheses Behavioural Ecology and Sociobiology 57:197-214

Hewes GW (1973) Primate communication and the gestural origin of language Current Anthropology 12:5-24

Higham JP, Hebets EA (2013) An introduction to multimodal communication Behavioral Ecology and Sociobiology 67:1381-1388

713 Hobaiter C, Byrne R (2011a) The gestural repertoire of the wild chimpanzee Anim Cogn 714 14:745-767 doi:10.1007/s10071-011-0409-2 
715 Hobaiter C, Byrne RW (2011b) Serial gesturing by wild chimpanzees: Its nature and function for communication Anim Cogn 14:827-838 doi:10.1007/s10071-011-0416-3

717 Hobaiter C, Byrne RW (2012) Gesture use in consortship: wild chimpanzees' use of gesture for an 'evolutionarily urgent'purpose Developments in Primate Gesture Research

719 Hobaiter C, Leavens DA, Byrne RW (2013) Deictic gesturing in wild chimpanzees (Pan troglodytes)? Some possible cases. Journal of Comparative Psychology $10.1037 / \mathrm{a} 0033757$

722

Hobaiter C, Byrne Richard W (2014) The Meanings of Chimpanzee Gestures Curr Biol 723 24:1596-1600 doi:10.1016/j.cub.2014.05.066

Hobaiter C, Byrne RW (2017) What is a gesture? A meaning-based approach to defining gestural repertoires Neuroscience \& Biobehavioral Reviews

Hobaiter C, Byrne RW, Zuberbühler K (2017) Wild chimpanzees' use of single and combined vocal and gestural signals Behavioral Ecology and Sociobiology 71:96 doi:10.1007/s00265-017-2325-1

Hobaiter C, Leavens DA, Byrne RW (2014) Deictic gesturing in wild chimpanzees (Pan troglodytes)? Some possible cases Journal of Comparative Psychology 128:82

Jacob S, Rieucau G, Heeb P (2011) Multimodal begging signals reflect independent indicies of nestling condition in European starlings. Behavioural Ecology 22:1249-1255.

Katsu N, Yamada K, Nakamichi M (2017) Influence of social interactions with nonmother females on the development of call usage in Japanese macaques Animal Behaviour

Kendon A (2004) Gesture: Visible action as utterance. Cambridge University Press, Cambridge

Kersken V, Gómez JC, Liszkowski U, Soldati A, Hobaiter C (in press) A gestural repertoire of 1-2 year old human children: in seach of the ape gestures. Animal Cognition. 
740 Kuhl PK (2003) Human speech and birdsong: Communication and the social brain Proceedings of the National Academy of Sciences of the United States of America 100:9645-9646

Kuhl PK (2004) Early language acquisition: cracking the speech code Nature reviews neuroscience $5: 831$

Ladygina-Kohts NN (1935) Infant Chimpanzee and Human Child. A Classic 1935 Comparative Study of Ape Emotions and Intelligence. Oxford University Press, New

747 York.

Ladygina-Kohts NN, de Waal F, Wekker BT (2002) Infant chimpanzee and human child: A classic 1935 comparative study of ape emotions and intelligence. Oxford University

750 Press,

Laporte MNC, Zuberbühler K (2011) The development of a greeting signal in wild

752 chimpanzees Developmental Science 14:1220-1234 doi:10.1111/j.1467-

753 7687.2011.01069.x

Leavens DA, Bard KA, Hopkins WD (2017) The mismeasure of ape social cognition Anim 755 Cogn doi:10.1007/s10071-017-1119-1

Leavens DA, Hopkins WD (1998) Intentional communication by chimpanzees: A crosssectional study of the use of referential gestures Developmental Psychology 34:813-

758 822

Leavens DA, Hopkins WD (2005) Multimodal concomitants of manual gesture by

761 Leavens DA, Hopkins WD, Bard KA (2005a) Understanding the point of chimpanzee 762 pointing: epigenesis and ecological validity Current directions in psychological science 14:185-189 
Leavens DA, Russell J, Hopkins W (2010) Multimodal communication by captive chimpanzees (Pan troglodytes) Anim Cogn 13:33-40 doi:10.1007/s10071-009-0242-z

Leavens DA, Russell JL, Hopkins WD (2005b) Intentionality as measured in the persistence and elaboration of communication by chimpanzees (Pan troglodytes) Child Development 76:291-306

Liebal K, Schneider C, Errson-Lembeck M (2018) How primates aquire their gestures: evaltuating current theories and evidence. Animal Cognition.

Liebal K, Call J (2012) The origins of non-human primates' manual gestures Philosophical Transactions of the Royal Society B: Biological Sciences 367:118-128 doi:10.1098/rstb.2011.0044

Liebal K, Pika S, Call J, Tomasello M (2004) To move or not to move. How apes adjust to the attentional state of others Interaction Studies 5:199-219 doi:10.1075/is.5.2.03lie

Liebal K, Pika S, Tomasello M (2006) Gestural communication of orangutans (Pongo pygmaeus) Gesture 6:1-38 doi:10.1075/gest.6.1.02lie

Liebal K, Schneider C, Errson-Lembeck M (2018) How primates acquire their gestures: evaluating current theories and evidence Anim Cogn doi:10.1007/s10071-018-1187-x

Liebal K, Waller BM, Burrows AM, Slocombe KE (2013) Primate Communication: A Multimodal Approach. Cambridge University Press, Cambridge

Liebal K, Waller BM, Burrows AM, Slocombe KE (2014) Primate Communication: A Multimodal Approach. Cambridge University Press, Cambridge

Lonsdorf EV, Anderson KE, Stanton MA, Shender M, Heintz MR, Goodall J, Murray CM (2014a) Boys will be boys: Sex differences in wild infant chimpanzee social interactions Animal Behaviour 88:79-83 
Lonsdorf EV, Markham AC, Heintz MR, Anderson KE, Ciuk DJ, Goodall J, Murray CM (2014b) Sex differences in wild chimpanzee behavior emerge during infancy PLoS ONE 9:e99099 doi:10.1371/journal.pone.0099099

Maestripieri D (2009) Maternal influences on offspring growth, reproduction, and behavior in primates Maternal effects in mammals:256-291

Marler P (1961) The logical analysis of animal communication Journal of Theoretical Biology 1:295-317

Marler P (1997) Three models of song learning: Evidence from behavior Developmental Neurobiology 33:501-516

Matsumoto-Oda A, Tomonaga M (2005) "Intentional" control of sound production found in leaf-clipping display of Mahale chimpanzees Journal of Ethology 23:109-112

Maynard Smith J, Harper D (2003) Animal signals. Oxford University Press,

Møller A, Pomiankowski A (1993) Why have birds got multiple sexual ornaments? Behavioral Ecology and Sociobiology 32:167-176

Moore R (2015) Meaning and ostension in great ape gestural communication Anim Cogn 19:223-231 doi:10.1007/s10071-015-0905-x

Murray CM, Lonsdorf EV, Stanton MA, Wellens KR, Miller JA, Goodall J, Pusey AE (2014) Early social exposure in wild chimpanzees: Mothers with sons are more gregarious than mothers with daughters Proceedings of the National Academy of Sciences 111:18189-18194 doi:10.1073/pnas.1409507111

Nishida T (1980) The leaf-clipping display: A newly-discovered expressive gesture in wild chimpanzees Journal of Human Evolution 9:117-128

Parker JG, Asher SR (1987) Peer relations and later personal adjustment: Are low-accepted children at risk? Psychological bulletin 102:357 
811 Partan S, Marler P (1999a) Communication goes multimodal Science 283:1272-1273

812 doi:10.1126/science.283.5406.1272

813 Partan SR (2013) Ten unanswered questions in multimodal communication Behavioral

$814 \quad$ Ecology and Sociobiology 67:1523-1539

815 Partan SR, Marler P (1999b) Communication goes multimodal Science 283:1272-1273

$816 \quad$ doi: $10.1126 /$ science.283.5406.1272

817 Partan SR, Marler P (2005) Issues in the classification of multimodal communication signals

818 American Naturalist 166:231-245

819 Perlman M, Tanner JE, King BJ (2012) A mother gorilla's variable use of touch to guide her 820 infant Developments in Primate Gesture Research 6:55

821 Pika S (2008) Gestures of apes and pre-linguistic human children: Similar or different? First Language 28:116-140 doi:10.1177/0142723707080966

823 Pika S (2012) The case of referential gestural signaling: Where next? Communicative \& $824 \quad$ integrative biology 5:578-582

825 Pika S, Fröhlich M (2018) Gestural acquisition in great apes: The Social Negotiation Hypothesis Anim Cogn

827 Pika S, Liebal K, Tomasello M (2003) Gestural communication in young gorillas (Gorilla 828

829 gorilla): Gestural repertoire, learning, and use American Journal of Primatology 60:95-111 doi:10.1002/ajp.10097

Pika S, Liebal K, Tomasello M (2005) Gestural communication in subadult bonobos (Pan paniscus): Repertoire and use American Journal of Primatology 65:39-61

833 Pika S, Mitani J (2006) Referential gestural communication in wild chimpanzees (Pan 834 troglodytes) Curr Biol 16:R191-R192 doi:10.1016/j.cub.2006.02.037 
835 Pika S, Zuberbühler K (2008) Social games between bonobos and humans: evidence for shared intentionality? American Journal of Primatology 70:207-210

837 Plooij FX (1978) Some basic traits of language in wild chimpanzees? In: Lock A (ed) Action, gesture and symbol. Academic Press, London, pp 111-131

839 Plooij FX (1979) How wild chimpanzee babies trigger the onset of mother-infant play. In:

840 Bullowa M (ed) Before Speech. University Press, Cambridge, pp 223-243

841 Plooij FX (1984) The behavioral development of free-living chimpanzee babies and infants 842 Monographs on Infancy:207

843 Pollick AS, De Waal FBM (2007) Ape gestures and language evolution Proceedings of the National Academy of Sciences of the United States of America 104:8184-8189

845 Pollick AS, Jeneson A, de Waal FB (2008) Gestures and multimodal signaling in bonobos. In: The Bonobos. Springer, New York, pp 75-94

847 Roberts AI, Roberts SGB, Vick S-J (2014a) The repertoire and intentionality of gestural communication in wild chimpanzees Anim Cogn 17:317-336 doi:10.1007/s10071013-0664-5

850

Roberts AI, Vick S-J, Buchanan-Smith HM (2012) Usage and comprehension of manual 851 gestures in wild chimpanzees Animal Behaviour 84:459-470

852 doi:http://dx.doi.org/10.1016/j.anbehav.2012.05.022

Roberts AI, Vick S-J, Roberts SGB, Menzel CR (2014b) Chimpanzees modify intentional gestures to coordinate a search for hidden food Nat Commun 5 doi:10.1038/ncomms4088

Rowe C (1999) Receiver psychology and the evolution of multicomponent signals Animal Behaviour 58:921-931 doi:http://dx.doi.org/10.1006/anbe.1999.1242

858 Ruben RJ (1997) A time frame of critical/sensitive periods of language development Acta 859 oto-laryngologica 117:202-205 
860 Ruxton GD, Schaefer HM (2011) Resolving current disagreements and ambiguities in the

861

862

863

864

865

866

867

868

869

870

871

872

873

874

875

876

877

878

879

880

881

882

883

884 terminology of animal communication Journal of Evolutionary Biology 24:2574-2585 doi:10.1111/j.1420-9101.2011.02386.x

Savage-Rumbaugh ES, Wilkerson BJ, Bakeman R (1977) Spontaneous gestural communication among conspecifics in the pygmy chimpanzee (Pan paniscus). In: Bourne GH (ed) Progress in ape research. Academic Press, New York, pp 97-116

Schaller GB (1963) The Mountain Gorilla: Ecology and Behavior. University of Chicago Press, Chicago

Schaller GB (1965) The behaviour of the mountain gorilla. In: de Vore I (ed) Primate Behaviour: Field Studies of Monkeys and Apes. Holt, Rinehart and Winston, New York, pp 324-367

Scherer KR (1995) Expression of emotion in voice and music Journal of voice 9:235-248

Schneider C, Call J, Liebal K (2012a) Onset and early use of gestural communication in nonhuman great apes American Journal of Primatology 74:102-113 doi:10.1002/ajp.21011

Schneider C, Call J, Liebal K (2012b) What Role Do Mothers Play in the Gestural Acquisition of Bonobos (Pan paniscus) and Chimpanzees (Pan troglodytes)? International Journal of Primatology 33:246-262

Schneider C, Liebal K, Call J (2017) “Giving” and "responding” differences in gestural communication between nonhuman great ape mothers and infants Developmental psychobiology 59:303-313

Scott-Phillips T (2015) Meaning in animal and human communication Anim Cogn:1-5 doi:10.1007/s10071-015-0845-5

Seyfarth RM, Cheney DL (2017) The origin of meaning in animal signals Animal Behaviour 124:339-346 doi:https://doi.org/10.1016/j.anbehav.2016.05.020 
885 Snowdon CT, Hausberger M (eds) (1997) Social Influences on Vocal Development. Cambridge University Press, Cambridge

887 Tanner JE, Byrne R (1996) Representation of action through iconic gesture in a captive 888 lowland gorilla Current Anthropology 37:162-173

889 Tinbergen N (1963) On aims and methods of ethology Ethology 20:410-433

890 Tomasello M (1990) Cultural transmission in the tool use and communicatory signalling of 891 chimpanzees. In: Parker ST, Gibson KR (eds) 'Language' and Intelligence in Monkeys

892 and Apes: Comparative Developmental Perspectives. Cambridge University Press,

893 Cambridge, UK, pp 274-311

894 Tomasello M (2008) Origins of human communication vol 2008. MIT press, Cambridge, $895 \quad$ Massachusetts

896 Tomasello M, Call J (2018) Thirty years of great ape gestures Anim Cogn

897 doi:10.1007/s10071-018-1167-1

898 Tomasello M, Call J, Nagell K, Olguin R, Carpenter M (1994) The learning and use of 899

900 gestural signals by young chimpanzees: A trans-generational study Primates 35:137154 doi:10.1007/bf02382050

901 Tomasello M, Call J, Warren J, Frost GT, Carpenter M, Nagell K (1997) The ontogeny of 902 chimpanzee gestural signals: A comparison across groups and generations Evolution 903 of Communication 1:223-259 doi:10.1075/eoc.1.2.04tom

904 Tomasello M, George BL, Kruger AC, Jeffrey M, Farrar, Evans A (1985) The development 905 of gestural communication in young chimpanzees Journal of Human Evolution

906 14:175-186 doi:10.1016/s0047-2484(85)80005-1

907

Tomasello M, Gust D, Frost GT (1989) A longitudinal investigation of gestural 908 communication in young chimpanzees Primates 30:35-50 
909 Townsend SW et al. (2016) Exorcising Grice's ghost: an empirical approach to studying

910

911

912

913

914

915

916

917

918

919

920

921

922

923

924

925

926

927

928

929

930

931

932

933

intentional communication in animals Biological Reviews:n/a-n/a doi:10.1111/brv.12289

van Lawick-Goodall J (1967) Mother-offspring relationships in free-ranging chimpanzees. In: Morris D (ed) Primate ethology. Weidenfeld and Nicolson, London, pp 287-346

Van Lawick-Goodall J (1968) The behavior of free-ranging chimpanzees in the Gombe Stream Reserve Animal Behaviour Monographs 1:161-311

van Noordwijk MA, van Schaik CP (2005) Development of ecological competence in Sumatran orangutans American Journal of Physical Anthropology 127:79-94 doi:10.1002/ajpa.10426

Vihman MM (1996) Phonological development: The origins of language in the child. Applied language studies. Blackwell Publishing, Malden

Waller BM, Liebal K, Burrows AM, Slocombe KE (2013) How can a multimodal approach to primate communication help us understand the evolution of communication? Evolutionary Psychology 11:147470491301100305

Whiten A, Goodall J, McGrew WC, Nishida T, Reynolds V, Sugiyama Y, Tutin CEG, Wrangham RW, Boesch C (1999) Culture in chimpanzees. Nature 399: 682-685.

Wich SA, Utami-Atmoko SS, Setia TM, Rijksen HD, Schürmann C, van Hooff JA, van Schaik CP (2004) Life history of wild Sumatran orangutans (Pongo abelii) Journal of Human Evolution 47:385-398 doi:citeulike-article-id:207594

Wilke C, Kavanagh E, Donnellan E, Waller BM, Machanda ZP, Slocombe KE (2017) Production of and responses to unimodal and multimodal signals in wild chimpanzees, Pan troglodytes schweinfurthii Animal Behaviour 123:305-316 doi:http://dx.doi.org/10.1016/j.anbehav.2016.10.024

Wilson EO (1976) Sociobiology. Belknap, Cambridge, MA 
